\title{
INVESTIGATION OF CIPROFLOXACIN REMOVAL FROM AQUEOUS SOLUTION BY NANOFILTRATION PROCESS
}

\section{DOĞAN E.C.}

Received: 15/01/2016

Accepted: 17/03/2016

Available online: 19/04/2016
Kocaeli University, Department of Environmental Engineering 41380, Izmit,Kocaeli,Turkey

*to whom all correspondence should be addressed: e-mail: esracdogan@gmail.com

\section{ABSTRACT}

This study investigated the removal of ciprofloxacin (CIPRO) from aqueous solution at a concentration of $10 \mathrm{mg} \mathrm{l}^{-1}$ and the permeate flux behavior during dead-end stirred-cell filtration system using six type of commercially available loose and tight NF membranes (NP010, NP030, NF90, NF270, CK3001 and DS-5DK). The rejection of CIPRO and permeate flux value were evaluated according to the effects of different parameters such as volume reduction factor (VRF), membrane type, transmembrane pressure (TMP) and $\mathrm{pH}$. Contact angle and SEM measurements were also performed for the analysis of the pollution occurring in the pores and on the surfaces of the membranes. Filtration experiments for all membranes used indicated that the flux reached the steady state at VRF 3. CIPRO rejection was found to vary especially with both $\mathrm{pH}$ and membrane tightness. Despite the fact that, the loose NF membranes showed poor and variable CIPRO removal, the highest rejection was obtained with NF90 tight membrane at the original pH value ( $\mathrm{pH}$ 5.65) and 10 bar of applied pressure. NF90 membrane achieved 98.3\% TOC, 98.9\% COD, 96.9\% TDS and $95.7 \% E_{c}$ rejections at $24.39 \mathrm{I} \mathrm{m}^{-2} \mathrm{~h}^{-1}$ permeate flux at the predefined operating conditions.

Keywords: Antibiotics, Nanofiltration membranes, Removal of ciprofloxacin, Permeate flux,Retention mechanism

\section{Introduction}

Ciprofloxacin (CIPRO) is the second generation antibiotics in a group of drugs called fluoroquinolone which are active against gram-positive and gram-negative bacteria. It is used to fight against human and veterinary diseases as well as to treat different types of bacterial infections (Vasconcelos et al., 2009; Jiang et al., 2012; Jiang et al., 2013a; Rakshit et al., 2013; Zaviska et al., 2013; Zhou and Jiang, 2015). This antibiotic acts by inhibiting essential enzyme function for DNA production (Le-Minh et al., 2010); it has been identified among the top ten of high priority pharmaceuticals associated to the water cycle in general and as a key priority substance for an EU project on the elimination of pharmaceutical residues from point sources in the healthcare sector (Jiang et al., 2012).

CIPRO has a high aqueous solubility under various $\mathrm{pH}$ conditions and a higher stability in soil and wastewater systems (Jiang et al., 2013a). Due to its high wastewater-sludge partition coefficient (log $\left.k_{\mathrm{d}} \sim 4\right), 79-92$ percent of the initial concentration was removed in a wastewater treatment plant (WWTPs) by sorption onto sludge (De Witte et al., 2009; Martin et al., 2012). However, literature shows that its predominant removal mechanism in treatment plant was attributed to significant adsorption to sludge and/or flocs rather than biodegradation (Le-Minh et al., 2010; Jiang et al., 2013a). In light of its zwitterionic characteristics, it can be concluded that the adsorption of fluoroquinolones on activated sludge was mainly affected by the electrostatic repulsion rather than hydrophobic interaction (Genç et 
al., 2013). Concentrations of CIPRO in wastewater effluents and surface water were observed to range from ng to $\mathrm{mg} \mathrm{l}^{-1}$, with measured concentration near drug manufacturing plants as high as $50 \mathrm{mg} \mathrm{l}^{-1}$ (i.e. $0.15 \mathrm{mM}$ ) (Rakshit et al., 2013). CIPRO has a molecular weight of $331.4 \mathrm{~g} \mathrm{~mol}^{-1}$. CIPRO concentrations between 0.7 and $124.5 \mathrm{\mu g} \mathrm{l}^{-1}$ in hospital effluent (Jiang et al., 2012; Genç et al., 2013), between 249 and $405 \mathrm{ng} \mathrm{l}^{-1}$ in wastewater treatment plants have been reported (Zaviska et al., 2013). CIPRO was found in wastewater treatment plant effluents at concentrations of 313-568 $\mathrm{ng} \mathrm{l}^{-1}$ and up to $124.5 \mathrm{mg} \mathrm{l}^{-1}$ in hospital sewage water (De Witte et al., 2009). Although, the presence of trace levels ( $\mathrm{ng} \mathrm{I}^{-1}$ ) of CIPRO in wastewater effluents, receiving waters and drinking water sources led to negative impacts on ecological and human health (Comerton et al., 2008; Vasconcelos et al., 2009; Wu et al., 2013), effective removal of this compound from discharge streams to the environment becomes an important issue (Sun et al., 2011).

A number of promising wastewater treatment technologies have been used for removing CIPRO from wastewater, such as sorption and adsorption (Wu et al., 2010; Jiang et al., 2013a; Rakshit et al., 2013; Genç et al., 2013; Wu et al., 2013), membrane separation (Sun et al., 2011; Zaviska et al., 2013; Urtiaga et al., 2013), ozonation, oxidation and other photocatalytic degradation processes (De Witte et al., 2009; Vasconcelos et al., 2009; De Witte et al., 2010; Jiang et al., 2012; Jiang et al., 2013b; Zhou and Jiang, 2015). Notwithstanding the differences between degradation mechanisms of these oxidation processes, the byproducts formed may be the same, or at least, similar to each other (Vasconcelos et al., 2009). Since mineralization is evaluated to be not cost effective, advanced oxidation processes focus on partial degradation. However, degradation products can be more toxic than the parent compound or they can still have the same features as the parent compound (De Witte et al., 2010).

Nanofiltration (NF) and reverse osmosis (RO) processes are proper for the effective removal of a variety of micropollutants such as pharmaceuticals, personal care products, endocrine disrupting compounds and hormones (Comerton et al., 2008; Kimura et al., 2009; Urtiaga et al., 2013; Sadmani et al., 2014). Nevertheless NF process which is more economical than RO due to its lower operating pressures which will lead to less energy consumption (Swamy et al., 2013; Ravikumar et al., 2014) has shown more effective removal for low-molecular-weight compounds, predicting their rejection has posed challenges due to the fact that multiple mechanisms including adsorption, steric-hindrance effects, and electrostatic effects can be involved in this concurrently controlled removal (Shah et al., 2012).

This study examined and compared the rejection of CIPRO as a function of membrane type having wellcharacterized pore sizes of NF membranes with dead-end filtration system in laboratory scale. Some of the membranes used in this study were not examined in the literature previously for the removal of CIPRO from water. Experiments were conducted with three loose (NP010, NP030, CK3001) and three tight (NF90, NF270, DS-5DK) NF membranes which have different molecular weight cut off (MWCO). The effects of the membrane type and the main operating parameters (VRF, $\mathrm{pH}$ and TMP) on CIPRO rejection and the permeate flux were examined. Finally, the fouling on pores and the surface of NF membrane was characterized by contact angle and SEM measurements, respectively.

\section{Materials and methods}

\subsection{Aqueous Solutions}

Prior to experimental studies, the aqueous solutions were prepared by spiking CIPRO at a concentration of $10 \mathrm{mg} \mathrm{l}^{-1}$ with laboratory-grade Milli-Q pure water at $\mathrm{pH}$ 7. Unlike other studies reported in the literature, in this study higher CIPRO concentration in the feed was used to easily monitor the performance of each membrane for their CIPRO rejection in a short period. CIPRO with a purity higher than 99 percent was obtained from the Sanovel, pharmaceutical company in Turkey. This commercially available product contains no more than 0.2 percent by weight of the by-product contaminant fluoroquinolonic acid. The solubility of CIPRO is pH-dependent, ranging from $6.19 \mathrm{~g} \mathrm{l}^{-1}$ at pH 5 to $0.15 \mathrm{~g} \mathrm{l}^{-1}$ at $\mathrm{pH} 7$ at $37{ }^{\circ} \mathrm{C}$. Values for acid dissociation constants - $\mathrm{p} K_{\mathrm{a} 1}$ and $\mathrm{p} K_{\mathrm{a} 2}-$ of CIPRO are $5.90 \pm 0.15$ and $8.89 \pm 0.11$, respectively. The cationic form $\mathrm{CIPRO}^{+}$predominates due to protonation of the amine group in the piperazine moiety when the solution $\mathrm{pH}$ is below 5.90 as shown in Figure 1 . When the solution $\mathrm{pH}$ 
is above 8.89, the anionic form CIPRO prevails due to loss of a proton from the carboxylic group. When solution $\mathrm{pH}$ is between 5.90 and 8.89, the zwitterionic form $\mathrm{CIPRO}^{\circ}$ resulting from the charge balance of the two groups mentioned above is the dominant species (Genç at al., 2013). The physico-chemical properties of CIPRO were summarized in Figure 1.

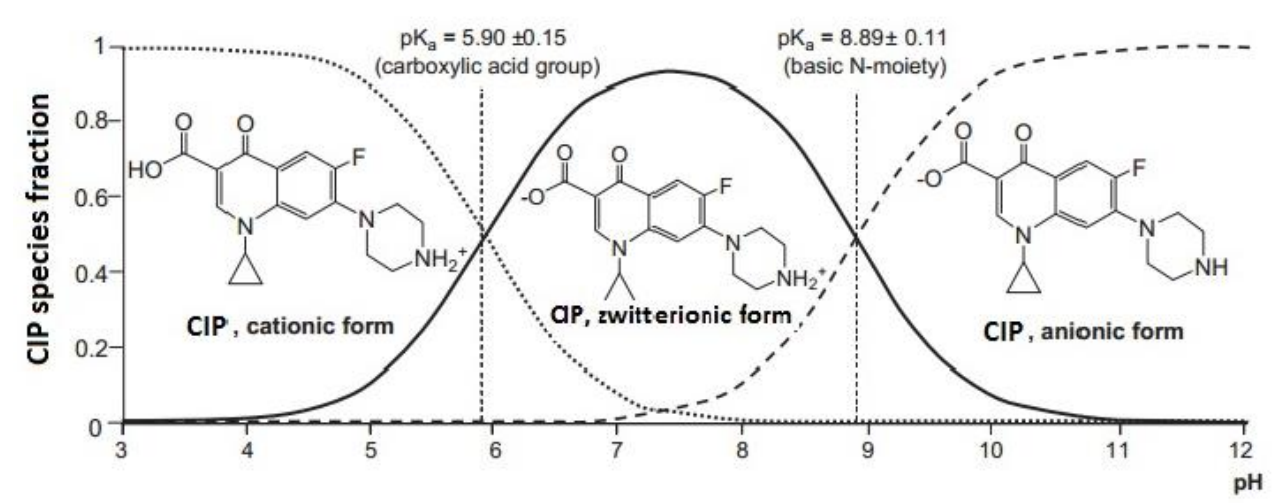

Figure 1. Molecular structure of CIP and its ionic forms as a function of $\mathrm{pH}, \mathrm{pK}_{\mathrm{a}}$ values (Genç et al., 2013)

Table 1. Physico-chemical properties of Ciprofloxacin (CIPRO) used (Vasconcelos et al., 2009; Jiang et al., 2012; Rakshit et al., 2013; Zhou and Jiang, 2015)

\begin{tabular}{cccc}
\hline Use & Structural formula & Chemical formula & $\begin{array}{c}\text { Dissociation constant } \\
\mathbf{p K}_{\mathrm{a}}\left(\mathbf{2 5}{ }^{\circ} \mathrm{C}\right)\end{array}$ \\
\hline $\begin{array}{c}\text { Antibiotic } \mathrm{B} \\
\begin{array}{c}\text { Antibiotic use in } \\
\text { chemoprevention }\end{array}\end{array}$ \\
\hline Appearance & Molecular weight $\left(\mathrm{g} \mathrm{mol}^{-1}\right)$ & $\begin{array}{c}\text { Water solubility } \\
\left(\mathbf{m g ~ l}^{-1}\right)\end{array}$ & Log $K_{\text {ow }}$ \\
\hline White crystalline & 331.35 & 30 & 0.28 \\
\hline
\end{tabular}

$d_{\mathrm{c}}(\mathrm{nm})=0.826$ (Zhou and Jiang, 2015)

$d_{\mathrm{c}}=$ Effective diameter of organic component in water, $\left(d_{\mathrm{c}}=0.065 \mathrm{MW}^{0.438}\right)$

\subsection{Membrane characterization}

Six different loose and tight NF membranes with high pressure including NP010, NP030, NF90, NF270, CK 3001 and DS-5DK were selected for this study and their detailed specifications were listed in Table 2. These membranes were chosen because they represent different molecular weight cut off values and inorganic and organic compound rejection performances. NP010 and NP030 membranes were hydrophilic polyethersulfone (PES) membranes that were obtained from Microdyn-Nadir, polyamide thin film composite (PTFC) membranes (NF90, NF270) were purchased from Dow Film Tech., and cellulose acetate membranes of CK 3001 and thin film composite membranes of DS-5DK were also obtained from GE Osmonics.

The hydrophilicity and hydrophobicity of surfaces of the membranes were measured by contact angle measurements which were carried out using an Attension Theta Lite Optical Tensiometer. Scanning electron microscope (SEM) was also used for determination of membrane surface morphologies using a 
JEOL Aqueous JSM-6060 LV microscope. SEM photographs were taken at different magnifications (in the range of $\times 400-5000)$.

\subsection{Membrane filtration system and set-up}

A dead-end filtration system (Aqueous HP4750 Stirred cell, Sterlitech Corporation, USA), made of stainless steel 316 with an inner diameter of $49 \mathrm{~mm}$ and an effective membrane area of $14.6 \mathrm{~cm}^{2}$, was used for all the filtration experiments. The volumetric capacity of the feed tank is $300 \mathrm{~mL}$ in which there is a stirrer with a stirring rate of $350 \mathrm{rpm}$. The pressure was set at 7-10-15 bar by nitrogen gas and the temperature was maintained at room temperature $\left(22^{\circ} \mathrm{C} \pm 1\right)$. Filtration processes were operated at the concentration mode, which means that permeate solution was not returned into the feed tank and the retentate became concentrated by accumulating in the feed tank. The volumetric flow rate of the permeate solution collected in a beaker was measured by an electronic balance (Precisa XT2220M-DR) and recorded by a computer. Afterwards, the permeate fluxes were calculated using RsKey Ver.1.34 software (A\&D Comp. Ltd., Japan). Initially, experiments were carried out until the volume reduction factor (VRF) value of 6 was reached for all the membranes used. Then, in the experiments conducted with tight membranes filtration experiments were performed until VRF 3 wherein the flux reached a steady state. Before starting the experiments, all NF membranes were passed through pure water at maximum pressure values given in literature for each membrane until when flux reached a constant. Removal of CIPRO at different operating conditions and water matrices by utilizing commercially available different NF membranes was examined in the laboratory set-up showed schematically in Figure 2.

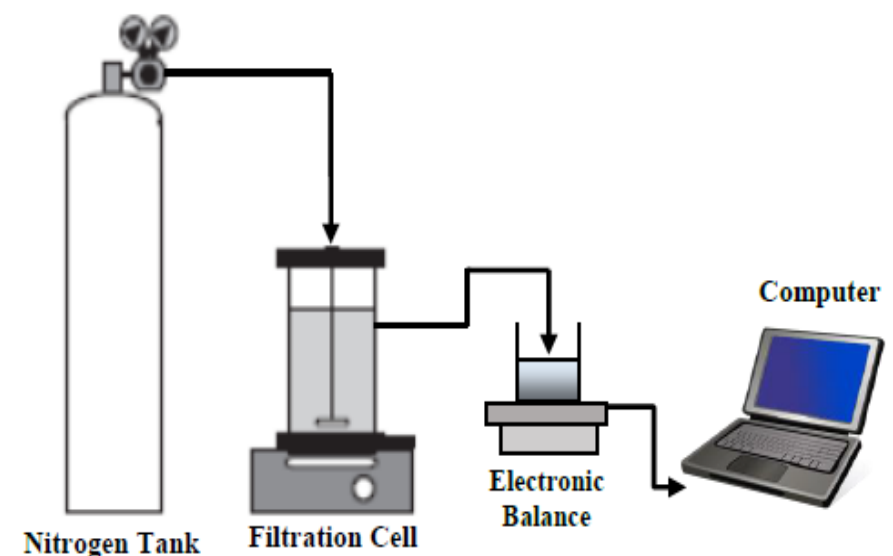

Figure 2. Experimental set-up of membrane system

\subsection{Analytical Procedure}

The total amount of removed organic substances in withdrawn aqueous-phase samples, was determined by measuring the total organic carbon (TOC). Total carbon was analyzed using a carbon analyzer (Teledyne Tekmar, aqueous Torch) in a measurement range of $30.000 \mathrm{mg} \mathrm{l}^{-1}$, detection limit of $50 \mathrm{\mu g} \mathrm{l}^{-1}$ and accuracy of maximum 1.5 percent. A high temperature catalytic oxidation method was applied at $750{ }^{\circ} \mathrm{C}$, which equipped with a high pressure NDIR detector. In all the analyses, three repeated measurements were taken for each sample, and the standard deviation was always below 1.5 percent. The average value of TOC concentration was reported. The COD was measured according to "Standard Methods for the Examination of Water and Wastewater" (APHA, 2005) by means of 5220 C-Closed reflux titrimetric method. Temperature, conductivity, TDS and $\mathrm{pH}$ were analyzed with the desktop multiparameter with Hach HQ440d (Hach-Lange GmBH). 
Table 2. General properties of the membranes used

\begin{tabular}{|c|c|c|c|c|c|c|c|c|c|}
\hline $\begin{array}{l}\text { Trade } \\
\text { name }\end{array}$ & Manufacturer & $\begin{array}{l}\text { Membrane } \\
\text { materials }\end{array}$ & $\begin{array}{l}\text { MWCO } \\
\text { (Da) }\end{array}$ & pH & $\begin{array}{c}\mathrm{MgSO}_{4} \\
\mathrm{Na}_{2} \mathrm{SO}_{4} \\
\text { Rejection } \\
\text { (\%) }\end{array}$ & $\begin{array}{l}\text { Pure water flux or } \\
\text { permeability }\left(25^{\circ} \mathrm{C}\right)\end{array}$ & $\begin{array}{c}\text { Maximum } \\
\text { Pressure } \\
\text { (Bar) }\end{array}$ & $\begin{array}{c}\text { Maximum } \\
\text { Temperature } \\
\left({ }^{\circ} \mathrm{C}\right)\end{array}$ & Reference \\
\hline NP 010 & Microdyn-Nadir & $\begin{array}{l}\text { Hydrophilic } \\
\text { polyethersulfone }\end{array}$ & 1000 & $0-14$ & $\begin{array}{c}25-55 \\
\mathrm{Na}_{2} \mathrm{SO}_{4}\end{array}$ & $>200 \mathrm{~L} \mathrm{~m}^{-2} \cdot \mathrm{h}^{-1}$ & 40 & 95 & (Ince et al., 2010) \\
\hline NP 030 & Microdyn-Nadir & $\begin{array}{l}\text { Hydrophilic } \\
\text { polyethersulfone }\end{array}$ & 400 & $0-14$ & $\begin{array}{l}80-95 \\
\mathrm{Na}_{2} \mathrm{SO}_{4}\end{array}$ & $>40 \mathrm{~L} \mathrm{~m}^{-2} \cdot \mathrm{h}^{-1}$ & 40 & 95 & (Ince et al., 2010) \\
\hline NF 270 & Dow Film Tech & Polyamide & $200-400$ & $2-11$ & $99.2 \mathrm{MgSO}_{4}$ & 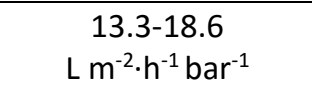 & 41 & 45 & $\begin{array}{c}\text { (Dolar et al., 2011; Shah et } \\
\text { al., 2012) }\end{array}$ \\
\hline DS-5DK & GE-Osmonics & $\begin{array}{l}\text { Thin Film } \\
\text { Composite }\end{array}$ & $150-300$ & $2-10$ & $96 \mathrm{MgSO}_{4}$ & 5.4-6.1 $\mathrm{L} \mathrm{m}^{-2} \cdot \mathrm{h}^{-1}$ bar $^{-1}$ & 41 & 50 & $\begin{array}{c}\text { (Hesampoura et al., 2010; } \\
\text { Bennani et al., 2012, }\end{array}$ \\
\hline NF90 & Dow Film Tech & Polyamide & $200-400$ & $2-11$ & $99 \mathrm{MgSO}_{4}$ & $6.4 \mathrm{~L} \mathrm{~m}^{-2} \cdot \mathrm{h}^{-1}$ bar $^{-1}$ & - & - & $\begin{array}{c}\text { (Dolar et al., 2011; Shah et } \\
\text { al., 2012) }\end{array}$ \\
\hline CK 3001 & GE-Osmonics & $\begin{array}{c}\text { Hyrophobic } \\
\text { cellulose acetate }\end{array}$ & 2000 & $2-8$ & $94 \mathrm{MgSO}_{4}$ & $3.01 \mathrm{~L} \mathrm{~m}^{-2} \cdot \mathrm{h}^{-1}$ bar $^{-1}$ & - & - & (Acero et al., 2010) \\
\hline
\end{tabular}




\subsection{Technical Analysis}

$\mathrm{NF}$ experiments were conducted at concentration mode, where permeate streams were collected in a separate unit and not returned into the feed water reservoir, whereas retentate was accumulated in the feed cell. VRF was calculated using Eq. (1).

$$
\mathrm{VRF}=\frac{V_{f}}{V_{c}}
$$

where $V_{f}$ and $V_{c}$ are the initial volume of the feed and the final volume of the concentrate, respectively.

The permeate fluxes $(J)$ were calculated by measuring the permeated water volume through the membrane and using Eq. (2).

$$
\mathrm{J}\left(\mathrm{L} / \mathrm{m}^{2} \mathrm{~h}\right)=\frac{1}{\mathrm{~A}} \frac{\mathrm{dV}}{\mathrm{dt}}
$$

where $A$ is the effective membrane filtration area $\left(\mathrm{m}^{2}\right), V$ is total volume of the permeate $\left(\mathrm{m}^{3}\right)$ and $t$ is filtration time (h), respectively (Can Doğan et al., 2015).

The rejection performance $(R)$ of each NF membrane on the basis of TOC which is a water quality parameter was derived from the following equations:

$$
R(\%)=\left(1-\frac{C_{p}}{C_{R}}\right) \times 100
$$

where $C_{p}$ is the TOC concentration in permeate $\left(\mathrm{mg} \mathrm{l}^{-1}\right)$ and $C_{R}$ is the TOC concentration in the cell after the filtration ( $\mathrm{mg} \mathrm{l}^{-1}$ ) (Can Doğan et al., 2015).

For the purpose of determining the amount of adsorbed CIPRO onto the membrane surface and into the membrane pores, the adsorption percentage ( $A P$ ) was calculated by the Eq. (4) (Acero et al., 2010):

$$
A P=\frac{\left(C_{f} V_{f}\right)-\left[\left(C_{p} v_{p}\right)+\left(C_{r} V_{r}\right)\right]}{\left(C_{f} V_{F}\right)} \times 100
$$

Adsorbed mass which was defined as the amount of solute adsorbed per unit membrane area onto the membrane surface and into the membrane pores was calculated using Eq.(5):

$$
M_{a d s}=\frac{\left(C_{f} V_{f}\right)-\left\lfloor\left(C_{p} v_{p}\right)+\left(C_{r} V_{r}\right)\right]}{A}
$$

where $C_{f}, C_{p}$ and $C_{r}$ are the feed, permeate and retentate TOC concentrations $\left(\mathrm{mg} \mathrm{l}^{-1}\right) ; V_{f}, V_{p}$ and $V_{r}$ are the feed, permeate and retentate volumes $\left(\mathrm{m}^{3}\right)$, respectively (Yoon et al., 2006).

\section{Results and discussion}

\subsection{Effect of VRF and membrane type on TOC rejection}

The first step in the filtration experiment was the filtration of distilled water with each clean membrane (NP010, NP030, CK3001, NF90, NF270, DS-5DK). In the following step, prepared aqueous solution with a concentration of $10 \mathrm{mg} \mathrm{l}^{-1}$ was subject to filtration until VRF 6 at a pressure of $10 \mathrm{bar}$, pH=5.65 (original $\mathrm{pH})$ and room temperature $\left(22 \pm 1{ }^{\circ} \mathrm{C}\right)$ using the general properties of membranes which were already described in Table 2. The flux values in Figure 3 obtained for different VRF values were 91.83, 23.67, 18.37 $\mathrm{L} \mathrm{m}^{-2} \mathrm{~h}$ for loose NP010, NP030, CK3001 membranes and $23.88 \mathrm{~L} \mathrm{~m}^{-2} \mathrm{~h}^{-1}, 65.70 \mathrm{~L} \mathrm{~m}^{-2} \mathrm{~h}^{-1}, 38.46 \mathrm{~L} \mathrm{~m}^{-2} \mathrm{~h}^{-1}$ for tight NF90, NF270, DS-5DK membranes, respectively. The maximum flux value was reached with NP010 
loose membrane having a pore size of $1000 \mathrm{Da} \mathrm{MWCO}$ and the maximum flux decline during the filtration was observed at a rate of $51.25 \%$ for NF90 membrane.

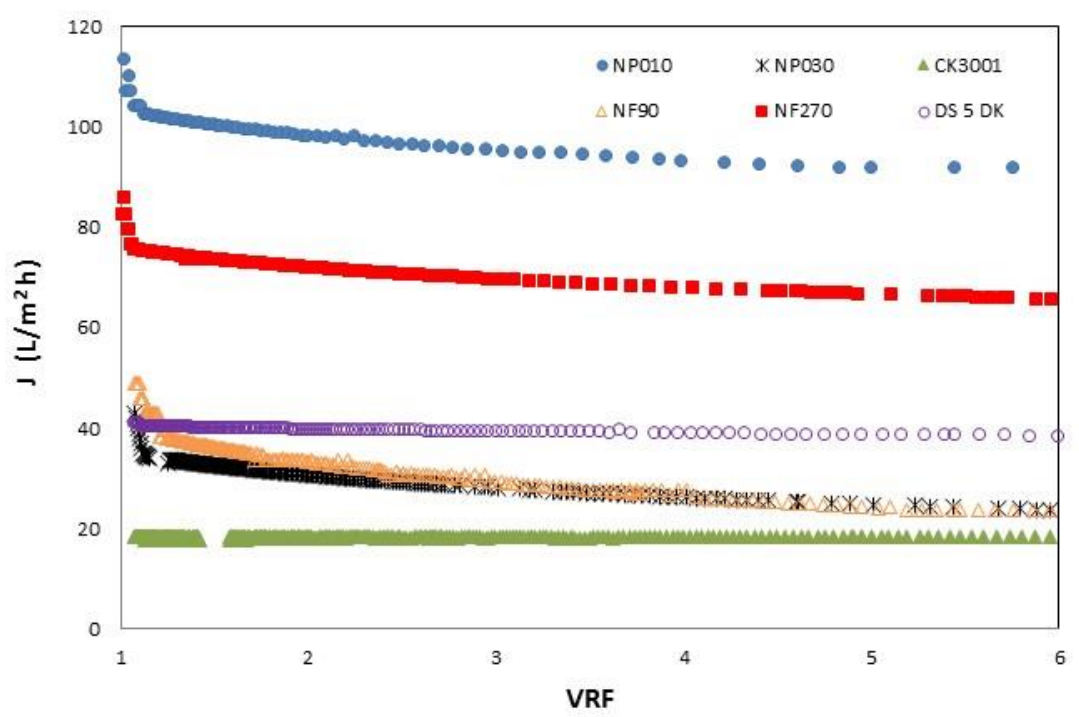

Figure 3. The flux decline as a function of VRF for different loose and tight NF membranes during the filtration of CIPRO aqueous solution (TMP: 10 bar, $\mathrm{pH}: 5.65$, temperature $22 \pm 1{ }^{\circ} \mathrm{C}$ )

As it can be observed from Figure 3, the permeate flux decreased drastically for NP010 and NF270 membranes until the VRF value reached 1.07-1.13 and for NP030 and NF90 membrane until the VRF value reached 1.15-1.20, then it slightly decreased until VRF 3 for all four membranes. Although, Acero et al., (2010) determined that adsorption is not the prevailing mechanism for micropollutant retention with NF membranes, the amounts of CIPRO adsorbed per unit membrane area were calculated for tight NF membranes as 10.4, 6.5 and $8.8 \mathrm{mg} \mathrm{cm}^{-2}$ with NF90, NF270 and DS-5DK membranes and the adsorption percentages were obtained as $7.2 \%, 4.5 \%$ and $6.1 \%$, respectively. Adsorption values for the loose membranes were at negligible levels. There was not any change in the flux values obtained against VRF for CK 3001 and DS-5DK membranes. Slight decrease of $J$ value followed by an almost constant values for higher VRF was a consequence of the causes of membrane fouling such as cake layer formation, pore blocking or the partial adsorption of CIPRO onto the membrane. The small decrease in $J$ indicated that low fouling effects occured with the selected membranes except NF90. It can be concluded that the higher decline of flux for NF90 membrane resulted from the formation of cake and concentration polarization occurring on the membrane surface in a short time due to the smaller size of the membrane pores. Similar results have been reported in literature (Yoon et al., 2006, Acero et al., 2010, Gönder et al., 2011).

The TOC rejections were given in Figure 4 as a function of membrane type during the filtration of CIPRO from aqueous solution for VRF 3 and VRF 6 at original $\mathrm{pH}$ and 10 bar of applied pressure. TOC rejections obtained on loose NP010, NP030 and CK 3001 membranes were 18.5\%, 15.4\% and 36.2\% for VRF 3, however, during the filtration experiments, removal efficiencies increased up to $26.7 \%, 37.5 \%$ and $70.5 \%$ for VRF 6, respectively. On the other hand, TOC rejections on tight NF90, NF270 and DS-5DK membranes obtained from polyamide material were $98.5 \%, 95.1 \%$ and $97.4 \%$ for VRF 3 and they increased up to 99.7\%, 97.2\% and $99.0 \%$ for VRF 6, respectively. Since NP010 membranes have both hydrophilic properties and large pore structures, they achieved low TOC rejections although they have high flux value. The flux value for NP030 membrane was lower, however higher TOC rejection was obtained due to its smaller pore size compared to the one for NP010. Due to its hydrophobic properties, flux values obtained for CK3001 membrane were too low despite its large pore structure. Despite the fact that the flux value of the CK 3001 membrane was lower than that of the NP010 and NP030 membranes, TOC rejections increased up to the level of $70 \%$ at VRF 6 because of its hydrophobic characterization. It is known from the literature that higher material retention was observed under concentrate mode in the loose 
membranes during the experiment-(Nghiem et al., 2007). This could be explained by the fact that, the rejection on the surface of the loose membranes was higher at VRF 6 compared to VRF 3 like it happened for CK3001 membrane. Cake layer formation functioned as a secondary membrane on the membrane surface at higher VRF value prevented the penetration of pollutants which eventually resulted slow flux decline and lower membrane fouling as reported by Gönder et al., (2011). Comerton et al. (2008) also emphasized that molecular weight was not much effective in removal of micropollutans due to large MWCO in loose membranes and there was not a significant correlation between the properties of the compound and the rejection. When TOC rejections were studied, tight polyamide membranes (NF90, NF270 and DS-5DK) showed higher performance than all loose membranes used. In the experiments conducted with tight membranes, it was observed that removal efficiencies did not change considerably with the increasing VRF values although TOC concentration in the retentate was much higher for VRF 6 compared to the one for VRF 3. This case explained the size exclusion occurred due to the small pore structure and having dense surface film on the top of a porous sub-layer, which possibly blocked diffusional transport across the membrane (Yoon et al., 2006; Yüksel et al., 2013). In accordance with these results, the optimum VRF value was determined as 3 .

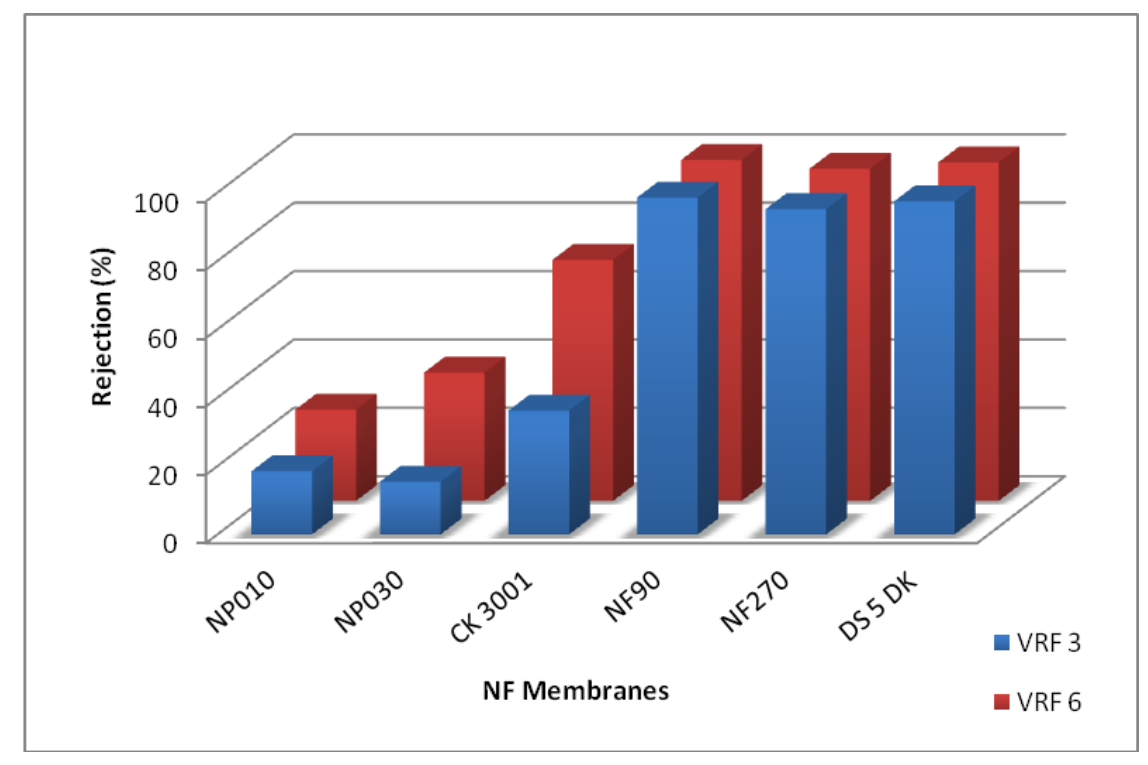

Figure 4. Evaluation of TOC rejection as a function of membrane type during the filtration of CIPRO aqueous solution for different VRF (TMP: 10 bar, $\mathrm{pH}: 5.65$, temperature $24 \pm 1^{\circ} \mathrm{C}$ )

\subsection{Effect of operating conditions on rejection}

Rejection of solutes on NF membranes will be affected by solute properties (molecular weight (MW), molecular size, dissociation constant $\left(\mathrm{p} K_{\mathrm{a}}\right)$ and octanol-water partition coefficient compounds $\left.\left(\log K_{\mathrm{ow}}\right)\right)$, membrane properties (molecular weight cut-off (MWCO), pore size, surface charge, hydrophobicityhydrophilicity and surface morphology), feed composition $(\mathrm{pH}$, ionic strength, hardness and the presence of organic matter) and also operating conditions. In addition, solutes can be rejected on NF membrane by one or a combination of three basic mechanisms including size exclusion (sieve steric effect), charge exclusion (electrical, Donnan), and physico-chemical interactions between solute, solvent and membrane (Yoon et al., 2006; Acero et al., 2010; Dolar et al., 2011; Sun et al., 2011; Vergili, 2013). Moreover it is also reported in the literature that size exclusion in tight membranes and charge exclusion and physicochemical interaction in the other membranes were more effective mechanisms in membrane filtration (Dolar et al., 2011).

In the second part of the study, effects of different pressure and $\mathrm{pH}$ operating conditions on COD, TDS and $E_{\mathrm{c}}$ removal efficiencies were investigated with TOC rejection for the selected VRF 3 value by utilizing tight membranes, with which the best removal was achieved. 


\subsubsection{Pressure}

The most critical factor in operating a membrane process is the applied pressure. To investigate whether the concentration polarization and fouling exist, experiments with varying TMPs were carried out. Filtration experiments were performed at different pressure values $(5,10,15$ bar) with tight NF90, NF270 and DS-5DK membranes for which the best removal efficiency was achieved at $22 \pm 1^{\circ} \mathrm{C}$, original $\mathrm{pH}$ and VRF 3. The flux values obtained at different pressures for each membrane were given in Figure 5 while the TOC rejections were given in Figure 6. Generally, the increase in applied pressure leads to an increase in both the initial and final flux values based on Darcy's law (Gönder et al., 2011). While this was observed for DS-5DK membrane, flux increase was not observed with the increasing applied pressure for the other two tight NF membranes.
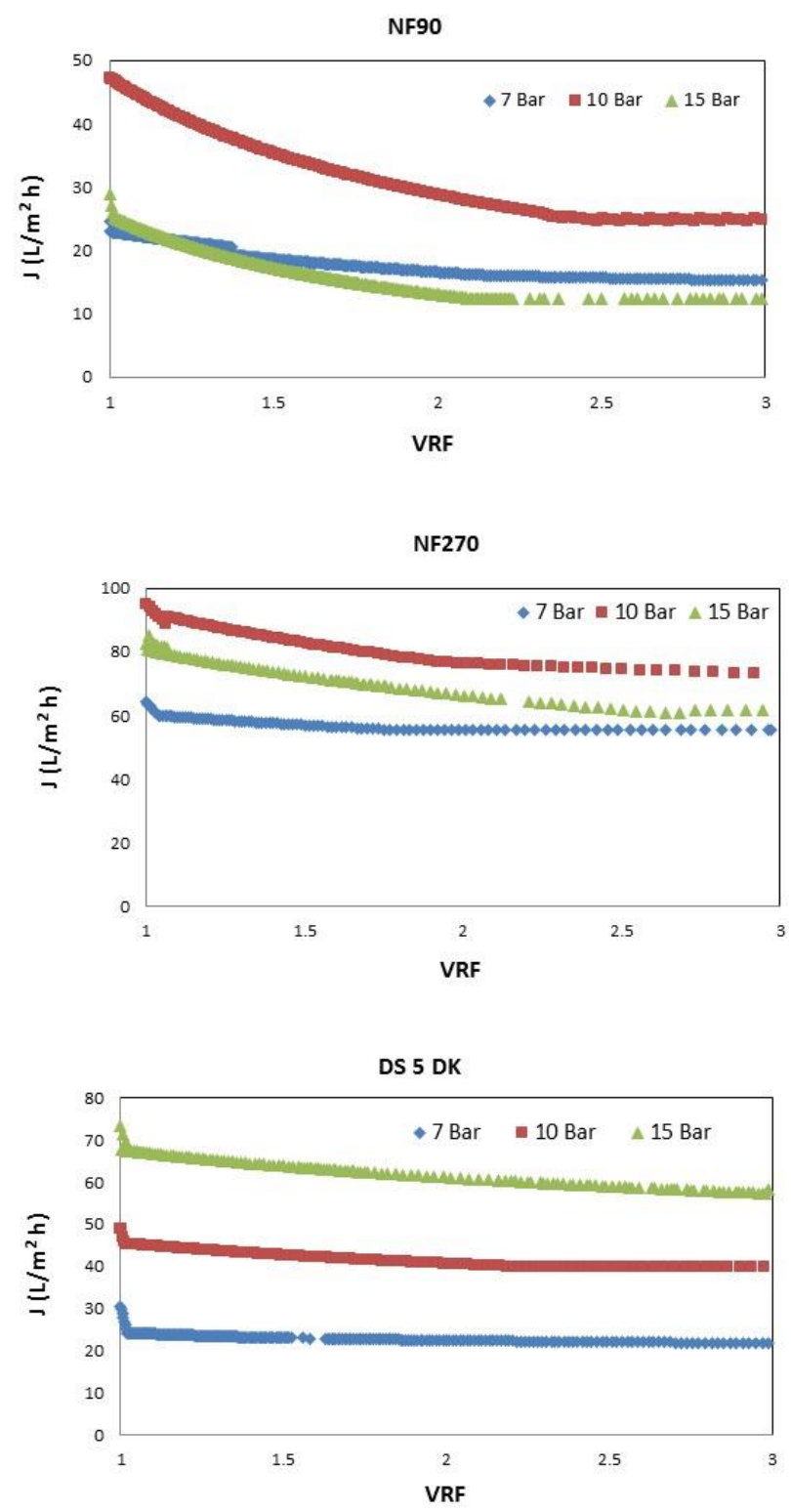

Figure 5. The flux decline as a function of VRF for different transmembrane pressures during the filtration of CIPRO sample solution ( $\mathrm{pH}: 5.65$, temperature $24 \pm 1^{\circ} \mathrm{C}$ ) NF90 (b) NF 270 (c) DS-5DK

According to Figure 5, it was determined that the higher flux values were obtained at 10 bar for NF90 and NF270 membranes, however, higher flux value was determined for DS-5DK membranes at 15 bar. During 
the experiments, the highest permeate flux decline was observed as the VRF increased with NF90 membrane at 10 and 15 bar. This was because, an increase in applied pressure could also contribute to membrane fouling that resulted from concentration polarization with flux decline as reported by Kaya et al., (2010). Then, more pollutants accumulated and cake layer formed onto the membrane surface. Although, flux values increased in parallel to the pressure increase in DS-5DK membrane, it was observed that intermediate blocking and fouling were present for all applied pressures until VRF 1.2. Later, the flux value stayed constant for all 3 pressure values.

It was demonstrated in Figure 6 that maximum TOC rejections were obtained at 10 bar for each three membrane and were found to be $98.7 \%, 91.2 \%$ and $97.1 \%$ for NF90, NF270 and DS-5DK membranes, respectively. When a comparison was made between the membranes, the maximum efficiency was achieved with NF90 membrane with $98.9 \%$ COD, 96.9\% TDS and $85.7 \% \mathrm{E}_{\mathrm{c}}$ at 10 bar applied pressure as it was given in Table 3. When COD and TDS removal efficiencies determined in this study were compared, the results obtained were similar to those obtained by Swamy et al. (2013) and Ravikumar et al. (2014). In addition, the decline of the flux from $47.24 \mathrm{~L} \mathrm{~m}^{-2} \mathrm{~h}^{-1}$ down to $21.43 \mathrm{~L} \mathrm{~m}^{-2} \mathrm{~h}^{-1}$ which was about 55 percent meant that there was more fouling in the pores and on the surface of NF90 membrane where size exclusion was effective for the removal of CIPRO with a molecular weight of $331.35 \mathrm{~g} \mathrm{~mol}^{-1}$. Nghiem et al. (2007) determined in their study that the main retention mechanism of the organic matter in filtration with negatively charged NF90 membranes was size exclusion. Another experimental study was conducted by Comerton et al. (2008) with different micropollutans where the dominant mechanism in the NF270 membranes was physico-chemical interaction with charge exclusion. However, in the filtration experiments conducted with NF270 membrane, it can be stated that the results were due to the concentration polarization occurred on the surface of the membrane and the membrane fouling which was also reported by Nghiem et al., 2007. This is due to the fact that there was no electrical interaction between membrane and the hydrophilic structure CIPRO which was present at water in uncharged state at original $\mathrm{pH}$ value.

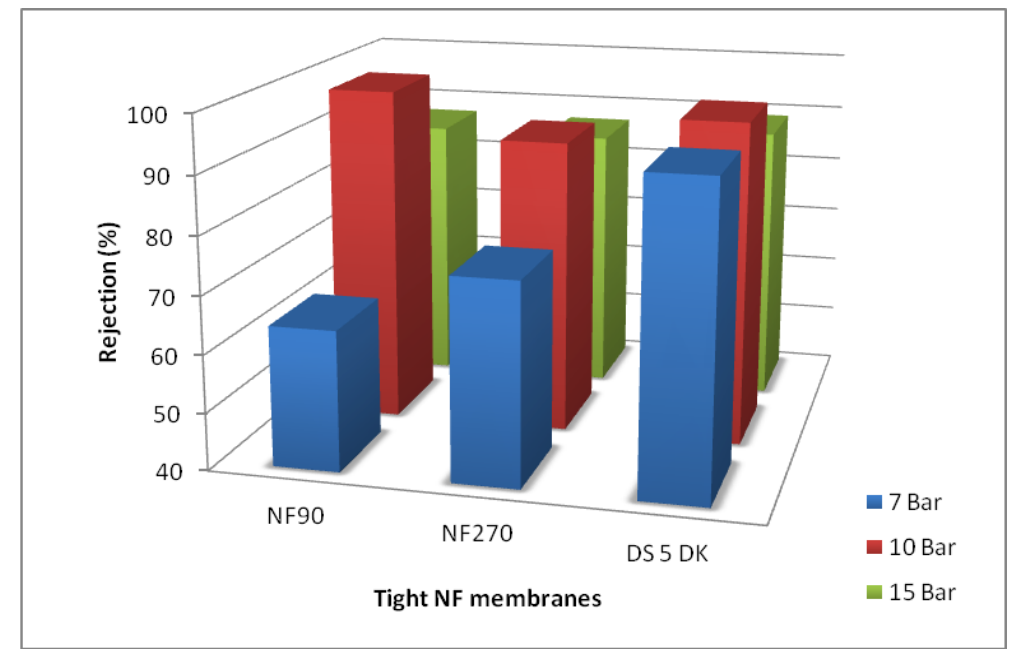

Figure 6. Effect of the TMP on TOC rejection for sample solution with different tight NF membranes for VRF 3

\subsection{2. $\mathrm{pH}$}

Generally, the reason for $\mathrm{pH}$ to significantly affect the removal mechanism in the membrane filtration is the fact that membrane surface charge and properties of the compounds change with pH (Nghiem et al., 2005; Yoon et al., 2006; Shah et al., 2012). Solubility changing with the $\mathrm{pH}$ of the solution, charge, dissociation constant $\left(\mathrm{p} K_{\mathrm{a}}\right)$, polarity, dipole moment and hydrophobicity expressed as the octanol-water partition coefficient compounds $\left(\log K_{\text {ow }}\right)$ are important physico-chemical properties that affect the rejection of the compounds and the membrane flux (Yoon et al., 2006; Nghiem et al., 2005; Vergili, 2013). 
The log $K_{\text {ow }}$ value was found to be the best parameter to describe the hydrophobic adsorption of the solutes to the membrane (Comerton et al., 2008). $\mathrm{p} K_{\mathrm{a}}$ value of the solute is an important parameter in the rejection of organic micropollutants, and it determines the charge of the solute in relation to the feed $\mathrm{pH}$ (Vergili, 2013). As defined in the literature, despite the low log $K_{\text {ow }}$ value (0.28) and hydrophilic property of CIPRO, the general characteristics of which were given in Table 2, its adsorption to membrane surface occurs very little, and the main rejection mechanism (beside the size exclusion) depends on membrane materials and solution $\mathrm{pH}$ which makes the study of CIPRO rejections at different $\mathrm{pH}$ values important.

Table 3. Membrane performances of sample water matrix at different transmembrane pressures for VRF 3 (Feed solution TOC: $7.99 \mathrm{mg} \mathrm{l}^{-1}$; COD: $39.6 \mathrm{mg} \mathrm{l}^{l^{-1}}$; $\mathrm{pH}: 5.65$;

\begin{tabular}{|c|c|c|c|c|c|c|c|c|c|c|c|c|}
\hline \multirow{3}{*}{$\begin{array}{l}\text { TMP } \\
\text { (Bar) }\end{array}$} & \multicolumn{4}{|c|}{ NF90 } & \multicolumn{4}{|c|}{ NF270 } & \multicolumn{4}{|c|}{ DS 5 DK } \\
\hline & \multirow{2}{*}{$\begin{array}{c}\text { Permeate } \\
\mathrm{pH}\end{array}$} & \multicolumn{3}{|c|}{$R(\%)$} & \multirow{2}{*}{$\begin{array}{c}\text { Permeate } \\
\mathrm{pH}\end{array}$} & \multicolumn{3}{|c|}{$R(\%)$} & \multirow{2}{*}{$\begin{array}{c}\text { Permeate } \\
\mathrm{pH}\end{array}$} & \multicolumn{3}{|c|}{$R(\%)$} \\
\hline & & COD & TDS & $E c$ & & COD & TDS & $E c$ & & COD & TDS & $E c$ \\
\hline 7 & 5.95 & 76.3 & 58.9 & 58.4 & 6.1 & 77.1 & 45.3 & 46.8 & 6.3 & 95.6 & 64.4 & 65.1 \\
\hline 10 & 6.3 & 98.9 & 96.9 & 85.7 & 6.4 & 93.6 & 77.7 & 78.2 & 6.3 & 97.3 & 81.5 & 81.0 \\
\hline 15 & 6.2 & 87.5 & 83.4 & 81.3 & 6.3 & 85.8 & 60.9 & 63.8 & 6.2 & 91.2 & 60.2 & 58.5 \\
\hline
\end{tabular}

To determine the optimum $\mathrm{pH}$ value with the tight membranes with which the best rejection was achieved at 10 bar applied pressure where the maximum rejection was obtained, synthetic aqueous solutions were subjected to filtration until VRF 3 . The solutions were prepared at four different $\mathrm{pH}$ values $(3,5.65,7.5$ and 11), in which ionic structure of CIPRO varies. The flux values obtained for each membrane were given in Figure 7. For NF90 membrane, the flux values obtained were close to each other except for $\mathrm{pH} 3$. The numbers were 9.18, 24.39, 21.47 and $21.84 \mathrm{I} \mathrm{m}^{-2} \mathrm{~h}^{-1}$ for $\mathrm{pH} 3,5.65,7.5$ and 11 , respectively. However, in this study, when utilizing NF90 membrane for filtration, the reason of permeate flux decrease of hydrophilic CIPRO, which is in cationic form in the solution at $\mathrm{pH} 3$ can be attributed to the fouling occurring in the pores and onto the surface of the membrane resulting due to the opposite charge effect. As a result of this fouling, cake formation occurred onto the membrane surface and the flux decreased. Lower flux decline was observed on NF270 and DS-5DK membranes. High permeate fluxes were obtained on NF270 membrane with a large pore size such as $94.19 \mathrm{I} \mathrm{m}^{-2} \mathrm{~h}^{-1}, 73.0 \mathrm{I} \mathrm{m}^{-2} \mathrm{~h}^{-1}, 58.83 \mathrm{I} \mathrm{m}^{-2} \mathrm{~h}^{-1}$, and 93.97 $\mathrm{I} \mathrm{m}^{-2} \mathrm{~h}^{-1}$ at $\mathrm{pH} 3, \mathrm{pH} 5.65, \mathrm{pH} 7.5$, and $\mathrm{pH} 11$, respectively. Fluxes reached steady states for DS-5DK membranes at the values of $28.46 \mathrm{I} \mathrm{m}^{-2} \mathrm{~h}^{-1}, 39.68 \mathrm{I} \mathrm{m}^{-2} \mathrm{~h}^{-1}, 29.82 \mathrm{I} \mathrm{m}^{-2} \mathrm{~h}^{-1}$ and $46.16 \mathrm{I} \mathrm{m}^{-2} \mathrm{~h}^{-1}$ for $\mathrm{pH} 3,5.65$, 7.5 , and 11 , respectively.

TOC rejections given in Figure 8 showed that, the rejections at original $\mathrm{pH}$ values on three membranes were very much higher than the rejections at the other pH values. Urase et al., (2007) and Vergili (2013) determined that under suitable operating conditions, almost same rate of drugs was removed on the tight membranes and generally a removal efficiency of above 95 percent was obtained. In this study, TOC rejection was found to be above 90 percent for each three membrane at original $\mathrm{pH}$ value. The TOC rejections obtained at different $\mathrm{pH}$ values showed once more that not only the size exclusion mechanism but also physico-chemical interaction and electrostatic exclusion are also effective mechanisms for NF membranes. TOC rejections being below 70 percent for all the membranes at $\mathrm{pH}$ values $(\mathrm{pH} 7.5$ and 11), where CIPRO was charge-free or negatively charged, supported this fact. Low retention of negatively charged CIPRO on NF membranes at high $\mathrm{pH}$ values can also be explained with the increase of the number of negatively charged groups of the membrane surface as the $\mathrm{pH}$ value increased and electrostatic repulsion occurred. It was also reported by Yoon et al., 2006 and Zazouli et al., 2009. When a general evaluation was made in terms of TOC removal, the maximum removal was obtained with NF90 membrane with $98.3 \%$ at original $\mathrm{pH}$, and the minimum efficiency was observed with NF270 membrane with 91.2\%. Similar results were obtained in the literature; Shah et al., (2012) showed that NF90 membrane exhibited rejection greater than $>90 \%$ for two antibiotics (sulfamethoxazole and carbadox), whereas loose NF270 membrane exhibited lower rejection between 52 and $100 \%$. 

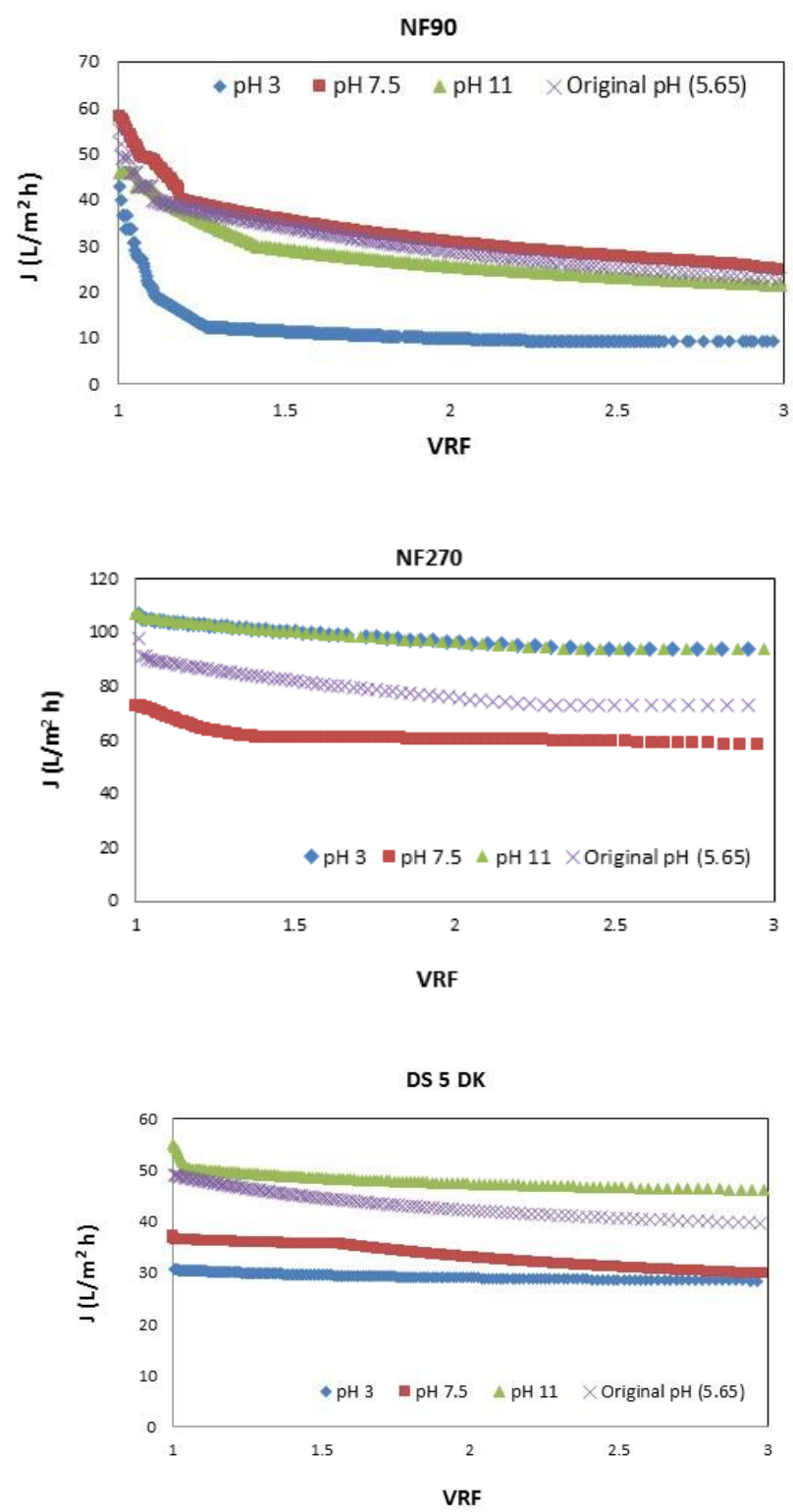

Figure 7. The flux decline as a function of VRF for different $\mathrm{pH}$ during the filtration of CIPRO sample solution (TMP: 10 Bar, temperature $24 \pm 1^{\circ} \mathrm{C}$ ) (A) 90 (b) NF 270 (c) DS-5DK

Removal efficiencies of COD and inorganic quality parameters from CIPRO sample solutions were given in Table 4 for each membrane at different $\mathrm{pH}$ values. It was clearly seen from these values that the rejections of other parameters changed based on $\mathrm{pH}$ like it was for TOC rejection.

CIPRO solution, which is in cationic form at original $\mathrm{pH}$ value, had more interaction with negatively charged NF90 membrane as a reslt of which removal efficiencies of some parameters reached at maximum levels such as $98.9 \%$ COD, $96.9 \%$ TDS and $95.7 \% E_{c}$ rejections. Besides, along with the $78.2 \%$ COD and $74.7 \%$ TDS and $76.3 \% E_{\mathrm{c}}$ removals, rejections of CIPRO on NF90 membrane at $\mathrm{pH} 7.5$ where it was in charge-free form in aqueous solution were in minimum levels. When the filtration mechanism at $\mathrm{pH} 11$ was examined, it was seen that negatively charged CIPRO compound in aqueous solution which was purified from proton, moved away from the membrane and COD removal efficiency reached to $84.8 \%$, solely because of the electrostatic repulsion. Yoon et al. (2006) also put emphasis on the rejection of uncharged trace organics on NF membranes that is influenced by steric hindrance, while the rejection of polar trace organics could be explained by electrostatic interactions with the charged membranes. 
Removal efficiencies were very much lower for NF270 membrane than NF90 membrane at all pH values, wherein COD, TDS and $E_{\mathrm{c}}$ parameters were $93.6 \%, 88.7 \%$ and $88.2 \%$ respectively, at original $\mathrm{pH}$ value. Rejections of COD and inorganic quality parameters decreased down to a level of 60 percent in case positive charge distribution increased in the aqueous solution of CIPRO at pH 3 for NF270 membranes. This result is same with that obtained by Nghiem et al., (2005) defining that salt (conductivity) retention also dropped dramatically as the electrostatic repulsion decreased at isoelectric point below $\mathrm{pH} 4$ in loose NF270 membrane. In the experimental study, while the removal rate was $25 \%$ at pH $3.5-4$, this rate increased up to $100 \%$ at pH 10 in the removal of sulfamethoxazole with NF270 membrane (Nghiem et al., 2005). As for NF90 membrane, removal efficiencies obtained at pH 7.5 and 11 were also at low levels for NF270 membrane. Besides rejections increased slightly due to the electrical repulsion at $\mathrm{pH} 11$, where CIPRO was purified from proton.

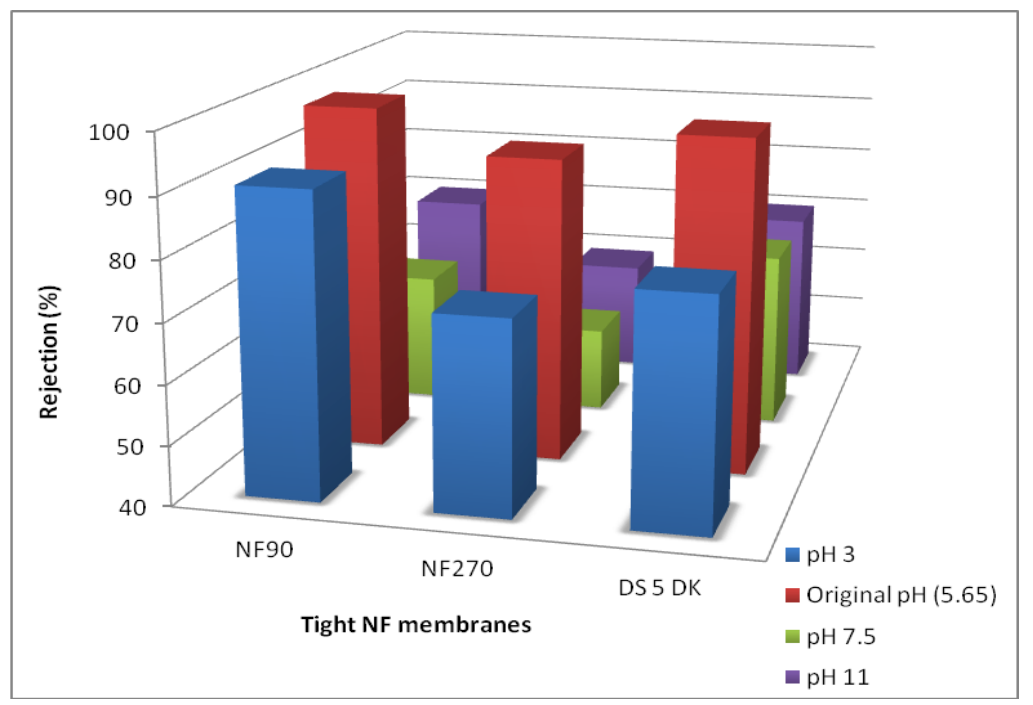

Figure 8. Effect of $\mathrm{pH}$ on TOC rejection coefficient for sample solution with different tight NF membranes for VRF 3

The situation was slightly different in DS-5DK membrane. While the maximum COD removal was observed with the rate of $97.3 \%$ at original $\mathrm{pH}$ value, $91.3 \%$ TDS and $90.5 \% E_{\mathrm{c}}$ rejections were obtained at $\mathrm{pH} 3$ where positively charged CIPRO released proton in aqueous solution.

Table 4. Membrane performances of sample water matrix at different $\mathrm{pH}$ for VRF 3 (Feed solution TOC: $7.99 \mathrm{mg} \mathrm{l}^{-1}$; COD: $39.6 \mathrm{mg} \mathrm{l}^{-1}$; pH: 5.65; TDS: $66.9 \mathrm{mg} \mathrm{l}^{-1}$; Conductivity: $139.8 \mu \mathrm{Sm}^{-1}$ )

\begin{tabular}{|c|c|c|c|c|c|c|c|c|c|c|c|c|}
\hline \multirow{3}{*}{$\begin{array}{c}\text { Feed } \\
\mathrm{pH}\end{array}$} & \multicolumn{4}{|c|}{ NF90 } & \multicolumn{4}{|c|}{ NF270 } & \multicolumn{4}{|c|}{ DS 5 DK } \\
\hline & \multirow{2}{*}{$\begin{array}{c}\text { Permeate } \\
\text { pH }\end{array}$} & \multicolumn{3}{|c|}{$\mathbf{R}(\%)$} & \multirow{2}{*}{$\begin{array}{c}\text { Permeate } \\
\text { pH }\end{array}$} & \multicolumn{3}{|c|}{$R(\%)$} & \multirow{2}{*}{$\begin{array}{c}\text { Permeate } \\
\text { pH }\end{array}$} & \multicolumn{3}{|c|}{ R (\%) } \\
\hline & & COD & TDS & $E c$ & & COD & TDS & Ec & & COD & TDS & $E c$ \\
\hline 3 & 3.7 & 93.2 & 89.7 & 89.3 & 3.2 & 62.5 & 58.7 & 57.0 & 3.7 & 83.8 & 91.3 & 90.5 \\
\hline 5.65 & 6.3 & 98.9 & 96.9 & 95.7 & 6.4 & 93.6 & 88.7 & 88.2 & 6.3 & 97.3 & 85.5 & 86.2 \\
\hline 7.5 & 6.2 & 78.2 & 74.7 & 76.3 & 6.7 & 55.6 & 60.0 & 60.4 & 8.2 & 73.0 & 79.7 & 78.1 \\
\hline 11 & 10.2 & 84.8 & 84.2 & 84.0 & 10.4 & 67.3 & 69.8 & 72.0 & 10.7 & 74.9 & 77.9 & 78.1 \\
\hline
\end{tabular}

When the effect of $\mathrm{pH}$ was examined by discussing the inorganic quality parameters in DS-5DK membrane, it was concluded that $\mathrm{pH}$ parameter was not that much effective in the rejection of inorganic quality parameters and the main mechanism was the size exclusion. Zazouli et al., (2009) determined in their study that the removal of neutral substances was mainly driven by the size exclusion, while for charged substances no systematic trends were observed, however; electrostatic interaction was a more dominant parameter in explaining the membrane rejection in the negatively charged compounds. 


\subsection{Membrane separation performance}

In order to determine the pollution in the surface of the NF90, NF270 and DS-5DK tight membranes with which the best removal was achieved, contact angle measurements were performed at 10 bar applied pressure and different $\mathrm{pH}$ values for VRF 3 . Moreover, the pollution occurring on the membrane pores at 10 bar and original $\mathrm{pH}$ value was determined with SEM analysis for three tight membranes.

Contact angles were measured by a sessile drop method called the water droplet method based on measuring the contact angles between the water droplet and the membrane surface. As the contact angle increases, hydrophobicity of the membrane increases. It is stated in the literature that hydrophobic membranes are more sensitive to pollution compared to the hydrophilic membranes (Yoon et al., 2006; Cho et al., 1999). In the experiments conducted with the clean membranes passed through pure water prior to the experimental study, the contact angles of the contaminated membranes were measured three times repetitively and the average values thereof were given in Figure 9.

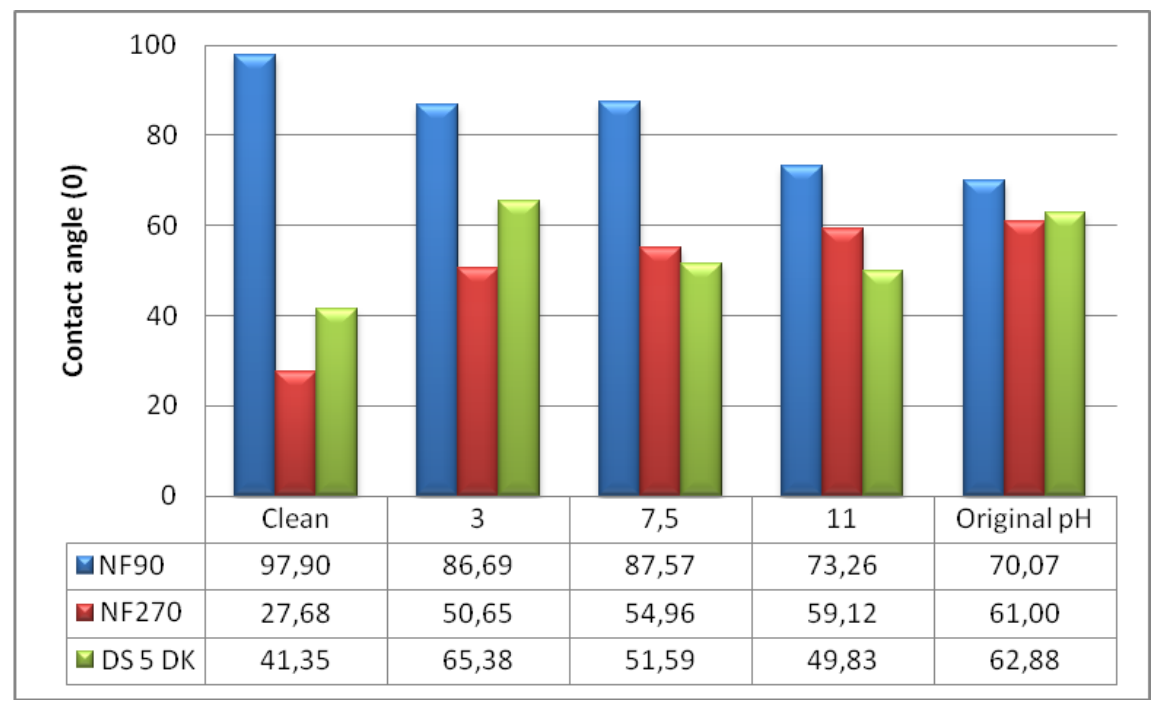

Figure 9. The contact angle results for all clean and fouled membranes (VRF 3, TMP: 10 Bar, temperature $22 \pm 1^{\circ} \mathrm{C}$ )

In the clean membranes, the membrane with the maximum contact angle was NF90 while the membrane with minimum contact angle was NF270 which has a large pore size. As a result of the contact angle measurements performed in clean and fouled membranes, contact angle values were lower in dirty NF90 membranes compared to the clean membranes while a reverse situation was observed in NF270 and DS5DK membrane. Accordingly, low contact angle values of the NF membranes may be attributable to the presence of a large number of $-\mathrm{OH}$ groups on the membrane surface. The low contact angle values of the NF90 membranes showed that the membranes were all hydrophilic. The contact angle of NF90 membrane, which was $97.9^{\circ}$ in the clean membrane, decreased down to $70.1^{\circ}$. Accordingly, it can be deduced that the fouling resulted from inorganic matters and the hydrophilicity increased after the fouling. The contact angle, which was $27.7^{\circ}$ in the clean membrane, increased up to $61.0^{\circ}$ for NF270 membrane at the same operating conditions while it increased from $41.4^{\circ}$ up to $62.9^{\circ}$ for DS-5DK membrane. As it is known that there is a direct proportion between hydrophobicity and contact angle (Vergili et al., 2013), it can be concluded that the hydrophobic property is dominant and these latter two membranes are more sensitive to pollution.

The pollution occurring onto the membrane pores were examined conducting SEM analysis in clean and fouled membranes for a more detailed examination of the pollution under operating conditions. SEM images of typical surface morphologies of all the NF membranes were shown in Figure 10.

The images showed that the surface of the NF90 membrane is heterogeneous and uneven without any crack. The coating and roughness with many modules are effective in the membrane surface. NF270 
membrane has a relatively homogeneous surface and there are some grooves on the surface which may be due to the very delicate and flexible character of the membrane. The surface of DS-5DK membrane is also homogeneous and continuous without any crack and has a much smoother surface than the others. Zhang et al. (2003) determined that the membrane surface properties were found to be correlated with membrane fouling. When the membranes used in this study were compared, it was observed that tight NF90 membranes are very rough and appear to consist of several layers. As defined in literature, according to Comerton et al., (2008), this is likely attributed to the roughness of their surfaces which are more prone to fouling in comparison to the smooth surface of the NF270 and DS-5DK membranes.

\section{NF90}

A

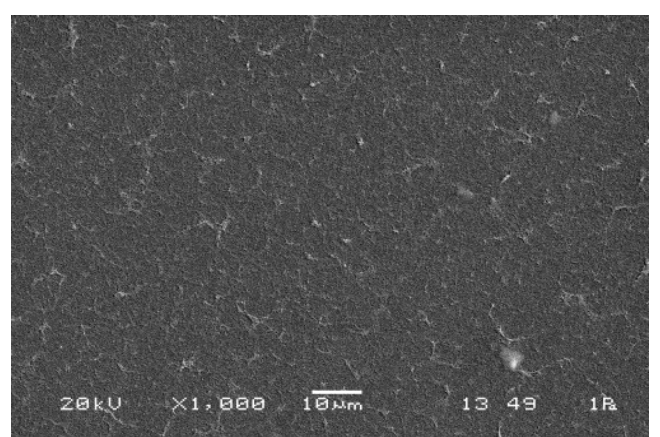

\section{NF270}

A

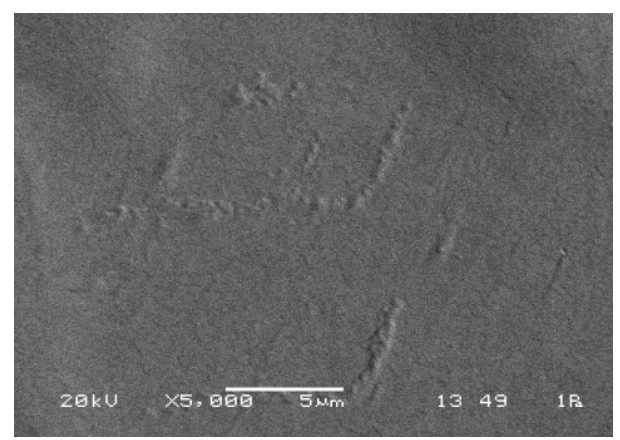

\section{DS-5DK}

A

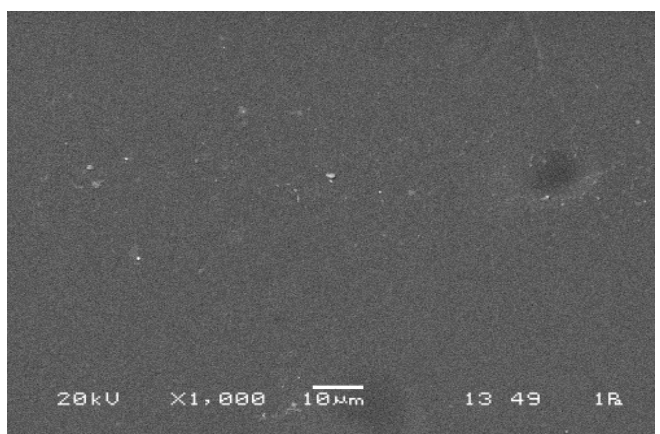

B

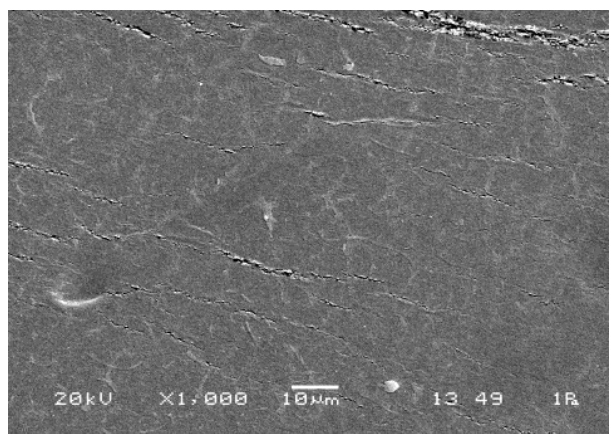

B

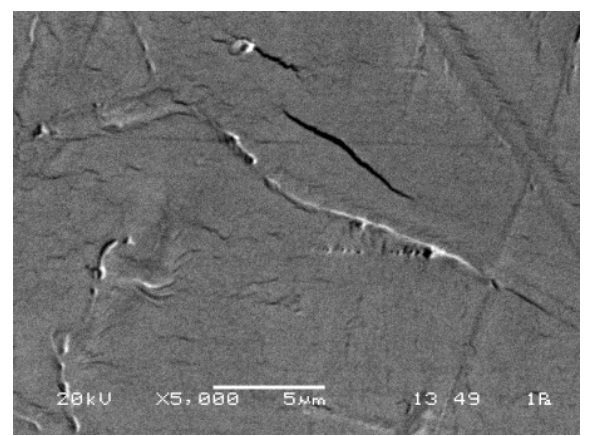

B

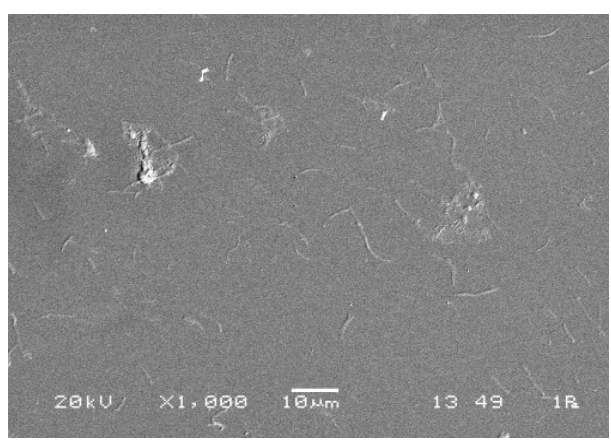

Figure 10. SEM images of typical surface morphologies of the NF membranes Cleaned membrane (A) Fouled membrane (B) 


\section{Conclusions}

In this study, the removal efficiency of CIPRO from aqueous solution at a concentration of $10 \mathrm{mg} \mathrm{l}^{-1}$ was investigated by utilizing six different commercial NF membranes while studying also the effect of various operating conditions. When TOC rejections were examined, better removal efficiencies $(\geq 90 \%)$ were obtained with tight membranes (NF90, NF270 and DS-5DK) when compared to the loose ones. Rejection of CIPRO by the 'loose' NF membrane was poor and variable, which showed that the membrane pore size was large relative to the compound size. Despite the decrease in the flux value, the maximum removal efficiencies with NF90 membrane were obtained with 98.9\% COD, 96.9\% TDS and 95.7\% $\mathrm{E}_{\mathrm{c}}$ along with 98.3\% TOC rejection for determinated operating conditions such as room temperature, original $\mathrm{pH}$ of 5.65, 10 bar applied pressure at VRF 3. According to the experimental studies conducted at different $\mathrm{pH}$ values, it was concluded that beside the size exclusion, the most effective operating parameter in the filtration of CIPRO (found in aqueous solution) with NF membranes is $\mathrm{pH}$. The reason of this is the fact that in the membrane filtration processes, $\mathrm{pH}$ affects the physico-chemical interactions between solute and generally negatively charged membrane surface.

\section{Acknowledgement}

This work was supported with a scientific research by [Kocaeli University] under Grant [number: BAP 2011/071] and [number: BAP 2014/043]

\section{References}

Acero J., Benitez F., Teva F. and Leal A. (2010), Retention of emerging micropollutants from UP water and a municipal secondary effluent by ultrafiltration and nanofiltration, Chemical Engineering Journal, 163, 264-272.

APHA, AWWA, (2005), Standart methods for the examination of water and wastewaters, $21^{\text {th }}$ Edition. American Public Health Association Publication, Washington, USA.

Bennani Y., Košutić K., Dražević E. and Rožić M. (2012), Wastewater from wood and pulp industry treated by combination of coagulation, adsorption on modified clinoptilolite tuff and membrane processes, Environmental Technology, 33, 1159-1166.

Can Doğan E., Yaşar A., Şen Ü. and Aydiner C. (2015), Water recovery from treated urban waswater by ultrafitration and reverse osmosis for landscape irrigation, Urban Water Journal, DOI: 10.1080/1573062X.2014.992917.

Cho J.W., Amy G. and Pellegrino J. (1999), Membrane filtration of natural organic matter: initial comparison of rejection and flux decline characteristics with ultrafiltration and nanofiltration membranes, Water Research, 33(11), 2517-2526.

Comerton A., Andrews R., Bagley D. and Hao C. (2008), The rejection of endocrine disrupting and pharmaceutically active compounds by NF and RO membranes as a function of compound and water matrix properties, Journal of Membrane Science, 313, 323-335.

De Witte B., Dewulf J., Demeestere K. and Langenhove H. (2009), Ozonation an advanced oxidation by the peroxone process of ciprofloxacin in water, Journal of Hazardous Materials, 161, 701-708.

De Witte B., Langenhove H., Demeestere K., Saerens K., Wispelaere P. and Dewulf J. (2010), Ciprofloxacin ozonation in hospital wastewater treatment plant effluent: Effect of $\mathrm{pH}$ and $\mathrm{H}_{2} \mathrm{O}_{2}$, Chemosphere, 78, 1142-1147.

Dolar D., Vukovic A., Asperger D. and Kosutic K. (2011), Effect of water matrices on removal of veterinary pharmaceuticals by nanofiltration and reverse osmosis membranes, Journal of Environmental Sciences, 23(8), 1299-1307.

Genç N., Can-Doğan E. and Yurtsever M. (2013), Bentonite for ciprofloxacin removal from aqueous solution, Water Science and Technology, 68(4), 848-855.

Gönder Z.B, Arayici S. and Barlas H. (2011), Advanced treatment of pulp and paper mill wastewater by nanofiltration process: Effects of operating conditions on membrane fouling, Separation and Purification Technology, 76, 292-302. 
Hesampoura M., Tanninen J., Reinikainen S.P., Platt S. and Marianne Nyströma (2010), Nanofiltration of single and mixed salt solutions: Analysis of results using principal component analysis (PCA), Chemical Engineering Research and Design, 88, 1569-1579.

Ince M., Senturk E., Onkal-Engin G. and Keskinler B. (2010), Further treatment of landfill leachate by nanofiltration and microfiltration-PAC hybrid process, Desalination, 255, 52-60.

Jiang J.-Q., Zhou Z. and Pahl O. (2012), Preliminary study of ciprofloxacin (CIP) removal by potassium ferrate(VI), Separation and Prufication Technology, 88, 95-98.

Jiang J.-Q., Zhou Z., Patibandla S. and Shu X. (2013b), Pharmaceutical removal from wastewater by ferrate(VI) and preliminary effluent toxicity assessments by the zebrafish embryo aqueous, Microchemical Journal, 110, 239-245.

Jiang W.-T., Chang P.-H., Wang Y.-S., Tsai Y., Jean J.-S., Li Z. and Krukowski K. (2013a), Removal of ciprofloxacin from water by birnessite, Journal of Hazardous Materials, 250/251, 362-369.

Kaya Y., Gönder Z.B., Vergili I. and Barlas H. (2010), The effect of transmembrane pressure and pH on treatment of paper machine process waters by using a two step nanofiltration process: Flux decline analysis, Desalination, 250, 150-157.

Kimura K., Iwase T., Kita S. and Watanable Y. (2009), Influence of residual organiz macromolecules produced in biological wastewater treatment processes on removal of pharmaceuticals by NF/RO membranes, Water Research, 43, 3751-3758

Le-Minh N., Coleman M., Khan S.J., van Luer Y., Trang T.T.T., Watkins G. and Stuetz R.M. (2010), The application of membrane bioreactors as decentralised systems for removal of endocrine disrupting chemicals and pharmaceuticals, Water Science and Technology, 61(5), 1081-1088.

Martin J., Camacho-Munoz D. and Santos J.L. (2012), Apariciol, Alonso E, Occurrence of pharmaceutical compounds in wastewater and sludge from wastewater treatment plants: Removal and exotoxicological impact of wastewater discharges and sludge disposal, Journal of Hazardous Materials, 239-240, 40-47.

Nghiem L. and Hawkes S. (2007), Effects of membrane fouling on the nanofiltration of pharmaceutically active compounds (PhACs): Mechanisms and role of membrane pore size, Separation and Purification Technology, 57, 176-184.

Nghiem L., Schafer A. and Elimelech M. (2005), Pharmaceutical retention mechanisms by nanofiltration membranes, Envronmental Science and Technology, 39, 7698-7705.

Rakshit S., Sarkar D., Elzinga E., Punamiya P. and Datta R. (2013), Mechanism of ciprofloxacin removal by nano-sized magnetite, Journal of Hazardous Materials, 246/247, 221-226.

Ravikumar L., Kalyani S., Satyanarya S. and Sridhar S. (2014), Processing pharmaceutical effluent condensate by nanofiltration and reverse osmosis membrane techniques, Journal of the Taiwan Institute of Chemical Engineers, 45(1), 50-56

Sadmani A., Andrews R. and Bagley D. (2014), Nanofiltration of pharmaceutically activeand disrupting compounds as a function of compounds interactions with DOM fractions and cations in natural water, Separation and Prufication Technology, 122, 462-471.

Shah A., Huang C. and Kim J. (2012), Mechanism of antibiotic removal by nanofiltration membranes: Aqueous development and application, Journal of Membrane Science, 389, 234-244.

Sun S.-P, Hatton T.-A and Chung T.-S. (2011), Hyperbranched polyethyleneimine induced cross-linking of polyamideimide nanofiltration hollow fiber membranes for effective removal of ciprofloxacin, Environmental Science and Technology, 45, 4003-4009.

Swamy B., Madhumala M., Prakasham R.S. and Sridhar S. (2013), Nanofiltration of bulk drug industrial effluent using indigenously develop functionalized polyamide membrane, Chemical Engineering Journal, 233, 193-200.

Urase T. and Sato K. (2007), The effect of deteriotion of nanofiltration membrane on retention of pharmaceuticals, Desalination, 202, 385-391.

Urtiaga A., Perez G., Ibanez R. and Ortiz I. (2013), Removal of Pharmaceuticals from a WWTP secondary effluent by ultrafiltration/reverse osmosis followed by electrochemical oxidation of the RO concentrate, Desalination, 331, 26-34.

Vasconcelos T., Kümmerer K., Henriques D. and Martins A. (2009), Ciprofloxacin in hospital effluent: Degradation by ozone and photoprocesses, Journal of Hazardous Materials 169, 1154-1158. 
Vergili I. (2013), Application of nanofiltration for the removal of carbamazepine, diclofenac and ibuprofen from drinking water sources, Journal of Environmental Management, 127, 177-187.

Wu Q., Li Z., Hong H., Yin K. and Tie L. (2010), Adsorption and intercalation of ciprofloxacin on montmorillonite, Applied Clay Science, 50(2), 204-211.

Wu S., Zhao X., Li Y., Zhao C., Du Qjuju, Sun J., Wang Y., Peng X., Xia Y., Wang Z. and Xia L. (2013), Adsorption of ciprofloxacin onto biocomposite fibers of graphene oxide/calcium alginate, Chemical Engineering Journal, 230, 389-395.

Yoon Y., Westerhoff P., Snyder S. and Wert E. (2006), Nanofilration and ultrafiltration of endocrine disrupting compounds, pharmaceuticals and personal care products, Journal of Membrane Science, 270, 88-100.

Yüksel S., Kabay N. and Yüksel M. (2013), Removal of bisphenol A (BPA) from water by various nanofiltration (NF) and reverse osmosis (RO) membranes, Journal of Hazardous Materials, 263, 307-310.

Zaviska F., Drogui P., Grasmick A., Azais A. and Heran M. (2013), Nanofiltration membrane bioreactor for removing pharmaceutical compounds, Journal of Membrane Science, 429, 121-129.

Zazouli M., Susanto H., Nasseri S. and Ulbricht M. (2009), Influences of solution chemistry and polymeric natural organic matter on the removal of aquatic pharmaceutical residuals by nanofiltration, Water Research, 43, 3270-3280.

Zhang W., He G., Gao P. and Chen G. (2003), Development and characterization of composite nanofiltration membranes and their application in concentration of antibiotics, Separation and Prufication Technology, 30, 27-35

Zhou Z. And Jiang J. (2015), Reaction kinetics and oxidation products formation in the degradation of ciprofloxacin and ibuprofen by ferrate(VI), Chemosphere, 119, 95-100. 